\title{
Comparison of Methods for Evaluating Surface Properties of Lung in Perinatal Period
}

\author{
GILLIAN GANDY, J. G. BRADBROOKE, B. T. NAIDOO, and DOUGLAS GAIRDNER \\ From the Cambridge Maternity Hospital
}

The discovery by Avery and Mead in 1959 that the lungs of infants dying from pulmonary hyaline membrane disease lacked surfactant, left still unexplained the cause of this deficiency. The facts then known, and those that have subsequently been added, would be compatible with a number of quite different hypotheses. The deficiency of surfactant might be either the cause of hyaline membrane disease, or merely the consequence. If the cause, the deficiency might be due to 'immaturity' of the system synthesizing it or releasing it after synthesis, or to a temporary failure of production of surfactant, consequent upon some perinatal stress such as fetal hypoxia.

Solution of the problem might be aided if a simple means were more generally available for testing lungs for the presence or absence of normal amounts of surfactant, since in most of the published work on the subject surface tension of lung extracts has been measured on the Wilhelmy surface balance, as modified by Clements (1957). This instrument is available in few laboratories, and is fairly timeconsuming to use, besides requiring 3-5 g. lung tissue for an estimation. Alternative methods are available, such as those that depend on the properties of air bubbles squeezed from lung tissue (Pattle, $1958,1965)$, or on the form of the pressure-volume curve after inflation of the lungs (Gruenwald, 1963a).

We have compared the results of assessing surface activity in lungs from cases of perinatal death, using 4 techniques. (1) Surface tension of saline extracts of lung measured on a surface balance. (2) Stability of bubbles expressed from a fragment of lung. (3) Presence or absence of 'clicking' in bubbles expressed from lung. (4) Pressure-volume relations of air-inflated lung.

Results were correlated with the histological findings, paying particular attention to the presence of pulmonary hyaline membrane.

Received April 20, 1967.

\section{Material and Methods}

A total of 90 infants was studied; 67 were born alive and 23 were stillborn. Birthweights ranged from $0 \cdot 45$ to $4.46 \mathrm{~kg}$., gestational age from 24 to 44 weeks, and the age of death of the liveborn infants from 1 hour to 14 days.

All four methods of investigating the lungs could not be applied to every case; the numbers of cases investigated are shown in Table $I$.

Necropsy was usually carried out 1-4 days after death (maximum 6 days), the body being refrigerated in the interval. The majority of lung surfactant studies were performed within 5 days of death (maximum 10 days). Routine histological sections of lung were obtained in all except 1 of the liveborn cases, but in only about half of the stillbirths. They were reviewed by one observer (G.G.); the presence or absence of hyaline membrane (HM) was noted and graded as a score of $0-4+$.

TABLE I

Numbers of Cases Investigated

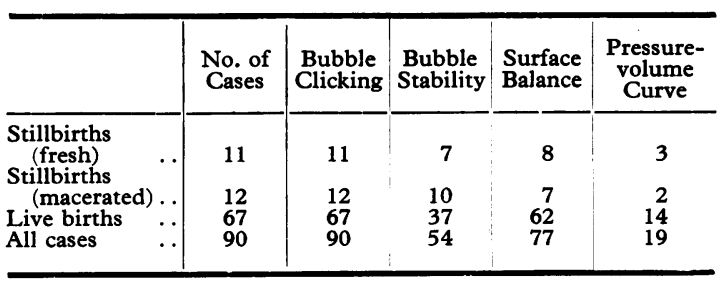

Bubble stability ratio. The method described by Pattle $(1958,1965)$ was followed. Air was injected into the lung either through a bronchus, or through a fine needle just beneath the pleural surface. After inflation, a small piece of lung was snipped off and squeezed into a drop of water on a coverslip. This was inverted over the well of a hollowed slide, moistened to provide a seal, and examined under the microscope. Bubbles with an initial diameter of 35-60 $\mu$ were observed over a 20-minute period, using a magnification of $\times 360$, which gave $2.5 \mu$ per division on a graticule 
in the eyepiece. When the initial and final diameters $\left(d_{1}\right.$ and $\left.d_{2}\right)$ of the bubbles had been recorded (identifying individual bubbles by means of a sketch), the result was expressed as a stability ratio, $\mathrm{SR}=\mathrm{d}_{2}{ }^{2} / \mathrm{d}_{1}{ }^{2}$, for each bubble. The mean SR was calculated for each batch of between 10 and 15 bubbles, usually 2 or 3 such batches from each case being examined. We have accepted Pattle's value of 0.6 as the lower limit of normal SR, and regarded 0.5 as borderline between normal and abnormal.

Bubble clicking. Pattle (1960) observed that if air bubbles expressed from normal lung were suspended in de-aerated water and watched under a miscrocope, they appeared to undergo a rhythmical series of slow expansions followed by sudden contractions, repeated at intervals of several seconds. This striking phenomenon he called clicking. In reality, the phase of slow expansion is a flattening of the bubble, and the contraction represents a sudden return to spherical shape, the bubble shrinking slightly at each contraction.

To detect clicking, after recording the bubble stability ratio, the coverslip with the hanging drop was removed, and the hollow in the lower slide filled with water which had been de-aerated by boiling and cooling. The coverslip was then replaced on the slide so that some of the bubbles from the hanging drop remained. The phenomenon of clicking is best seen in bubbles in the $100-200 \mu$ diameter range, using a magnification of about $\times 90$.

Surface tension measurements. Air was injected into the piece of lung to be examined, as described above. About $5 \mathrm{~g}$. were minced finely with scissors, stirred with $0.9 \%$ saline for 5-10 minutes, filtered through gauze, and the volume made up to $50 \mathrm{ml}$. The crude lung extract was then placed in the trough of a modified Wilhelmy balance, and allowed to stand for 15-30 minutes before cyclical compression and expansion of the surface film was started. The rate of barrier movement was sinusoidal, being most rapid at midcompression or expansion. In the earlier experiments the cycles were of 13 minutes' duration, but in later ones the speed was altered to give a cycle of 5 minutes. The area at full compression was $20 \%$ of that at full expansion. Surface tension/surface area loops were automatically recorded on paper. The material was usually left in the trough, at room temperature, until no further decrease in minimum surface tension $\left(T_{\min }\right)$ could be observed at minimal area. This period averaged 3 hours, but ranged from $\frac{1}{2}$ to 24 hours, though it was rare to find any further diminution in $T_{\min }$ after 12 hours. We have followed earlier workers in taking a value for $T_{\min }$. of 15 dynes $/ \mathrm{cm}$. as the upper limit for normal lung tissue. In presenting our results diagrammatically, however, we have expressed values of $T_{\text {min. }}$. to the nearest multiple of 5 , so that in Fig. 2 and 3 cases shown as $T_{\min }=15$ dynes $/ \mathrm{cm}$. include all those within the range of 13-17 dynes/cm. In fact, however, only 3 out of 77 cases gave borderline values of 16 or 17 dynes $/ \mathrm{cm}$.
Pressure-volume curve. A cannula was tied into the bronchus of one lung and connected to a T-piece, one limb of which went to a water manometer, and the other to a syringe. The lung was inflated with air from the syring $\epsilon$ in increments of from 0.5 to $2.5 \mathrm{ml}$, depending on the size of the lung, to a maximum pressure of $45 \pm 5 \mathrm{~cm} . \mathrm{H}_{2} \mathrm{O}$, and was then deflated by similar series of steps to zero pressure. At each increment about one minute was allowed to elapse for equilibrium to be attained, before the pressure was read. By performing a dummy run with the cannula to the lung closed, the volume of air filling the limb of the manometer at varying pressures was measured, enabling a correction for this to be made. In many cases leaks occurred which could sometimes be dealt with by clamping off a small area of lung involved, or by using only one lobe of a lung (Gruenwald, 1963a). But in many other cases leaks could not be dealt with in these ways, and the investigation had then to be abandoned.

Gruenwald (1963a) has shown that the shape of the pressure-volume curve during deflation most effectively differentiates normal from abnormal lung in respect to its surface properties. He has defined (Gruenwald, 1963b) a stability index (L) which provides a quantitative measure of the ability of lung to retain air during deflation:

$$
\mathrm{L}=\left(2 \mathrm{~V}_{5}+\mathrm{V}_{10}-3 \mathrm{~V}_{0}\right) / 2\left(\mathrm{~V}_{\max }-\mathrm{V}_{0}\right) \text {, }
$$

where $\mathrm{V}_{\text {max., }}, \mathrm{V}_{10}, \mathrm{~V}_{5}$, and $\mathrm{V}_{0}$ are the volumes of air retained at maximum pressure $\left(45 \pm 5 \mathrm{~cm} . \mathrm{H}_{2} \mathrm{O}\right.$ in this instance), at $10 \mathrm{~cm} . \mathrm{H}_{2} \mathrm{O}$ pressure, at $5 \mathrm{~cm} . \mathrm{H}_{2} \mathrm{O}$ pressure, and at zero pressure. Gruenwald (1963a) found that the value of $L$ for normal lung was above $0 \cdot 8$. Unlike Gruenwald, we did not degass lung before inflation, and the lungs were inflated to about $45 \mathrm{~cm} . \mathrm{H}_{2} \mathrm{O}$ pressure rather than to 60 . Possibly for these reasons our values for $L$ have been slightly lower, with normals $0 \cdot 7$ or over.

\section{Results}

Bubble clicking, bubble stability ratio, and minimum surface tension of lung extracts. Fig. 1, 2, and 3 show the relation between each pair of these three methods for investigating surface activity in saline extracts of lung. Fig. 1 shows that amongst 54 cases there was good concordance between the two methods employing bubbles. All 32 cases having a normal bubble SR of 0.6 or more gave bubbles which clicked, and all 19 cases with a clearly abnormal SR of 0.3 or less gave bubbles which did not click. 3 cases gave a borderline value for SR of 0.5 ; the bubbles of 2 clicked and of 1 did not click.

Fig. 2 shows that of 77 cases where the surface tension was measured, 50 fell within the normal range $\left(T_{\min } .15\right.$ dynes $/ \mathrm{cm}$. or less), and all except 1 of these showed bubble clicking. Of the 27 cases which fell outside the normal range $\left(T_{\min }\right.$. 20 dynes/cm. or more), all except 3 gave bubbles 


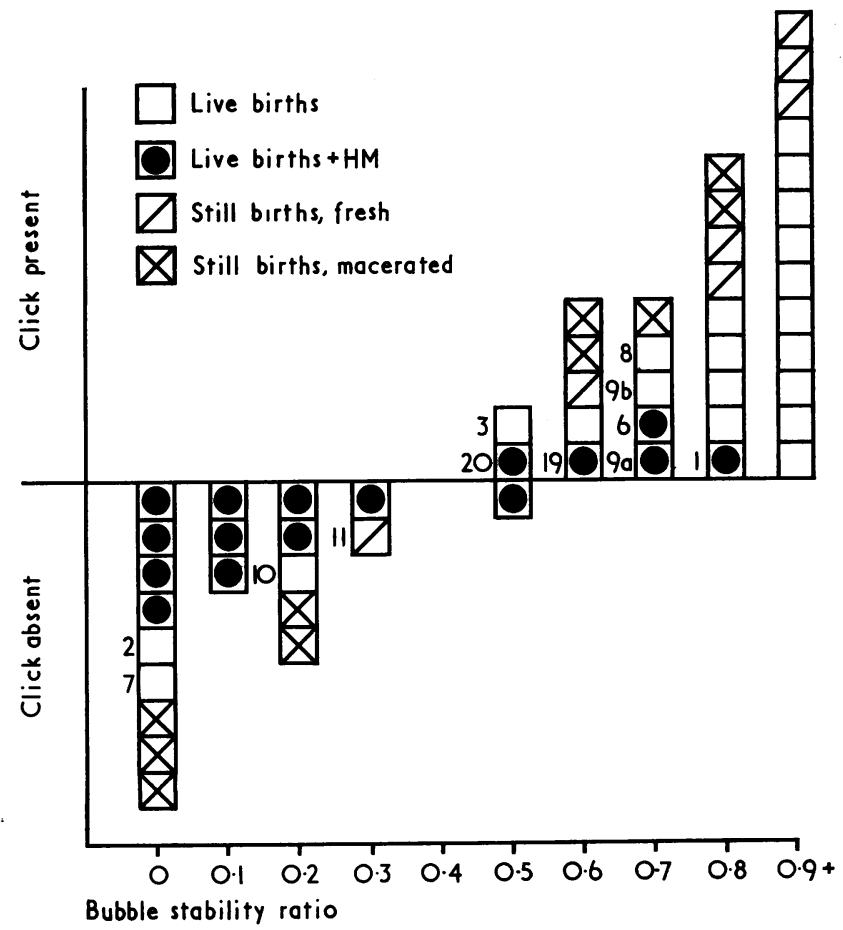

FIG. 1.-Bubble stability vs. presence or absence of bubble clicking in lung extracts from 54 perinatal deaths. The numbers identify individual cases referred to in the text and Tables.

TABLE II

Details of 11 Cases with Discordances in Surfactant Evaluation

\begin{tabular}{|c|c|c|c|c|c|c|c|c|c|}
\hline $\begin{array}{l}\text { Case } \\
\text { No. }\end{array}$ & $\begin{array}{c}\text { Age } \\
\text { at } \\
\text { Death }\end{array}$ & $\begin{array}{l}\text { Gest'n } \\
\text { (wk.) }\end{array}$ & $\begin{array}{l}\text { Weight } \\
\text { (kg.) }\end{array}$ & $\begin{array}{l}\text { Bubble } \\
\text { SR }\end{array}$ & $\begin{array}{l}\text { Bubble } \\
\text { Click }\end{array}$ & $\begin{array}{l}\text { Tmin. } \\
\text { (dynes/ } \\
\text { cm.) }\end{array}$ & $\mathbf{L}$ & HM & Remarks \\
\hline$\frac{1}{2}$ & $\begin{array}{l}4 \mathrm{dy} . \\
2 \mathrm{hr} .\end{array}$ & $\begin{array}{l}31 \\
27\end{array}$ & $\begin{array}{l}1 \cdot 60 \\
0.64\end{array}$ & $\begin{array}{l}0.79 \\
0.03\end{array}$ & + & $\begin{array}{l}18 \\
18\end{array}$ & 二 & $2+$ & $\begin{array}{l}\text { RDS surviving } 4 \text { dy. } \\
\text { 'Previable' infant dying at } 2\end{array}$ \\
\hline 3 & $7 \mathrm{hr}$. & 24 & 0.56 & 0.53 & + & 19 & 0.86 & - & $\begin{array}{l}\text { Abnormal Tmin. and SR val- } \\
\text { ues ? related to extreme }\end{array}$ \\
\hline 4 & $18 \mathrm{hr}$. & 34 & $1 \cdot 90$ & - & + & 27 & 一 & $3+$ & $\begin{array}{l}\text { prematurity } \\
\text { RDS; bubble clicking ex- }\end{array}$ \\
\hline 5 & $3 \mathrm{dy}$. & 40 & $3 \cdot 07$ & - & + & 12 & - & $3+$ & $\begin{array}{l}\text { ceptionally present } \\
\text { Transposition of great ves- } \\
\text { sels; HM presumably } \\
\text { related to heart failure, } \\
\text { since surface activity nor- } \\
\text { mal }\end{array}$ \\
\hline 6 & $2 \mathrm{dy}$. & 40 & $3 \cdot 30$ & $0 \cdot 73$ & + & 13 & 一 & $2+$ & Massive intra-alveolar hae- \\
\hline 7 & $1 \mathrm{hr}$. & 33 & $1 \cdot 64$ & 0.03 & 0 & 21 & $0 \cdot 20$ & 0 & $\begin{array}{l}\text { morrnage } \\
\text { Massive intra-alveolar hae- }\end{array}$ \\
\hline 8 & $3 \mathrm{dy}$. & 38 & $2 \cdot 44$ & $0 \cdot 77$ & + & 9 & 0.43 & 0 & $\begin{array}{l}\text { morrhage; renal agenesis } \\
\text { Low L value probably mis- }\end{array}$ \\
\hline$\stackrel{9 a}{9 \text { (Twin 1) }}$ & $4 \mathrm{dy}$. & 28 & $1 \cdot 04$ & $0 \cdot 72$ & + & 15 & - & $1+$ & $\begin{array}{l}\text { leading } \\
\text { On IPPR; at necropsy mas- } \\
\text { sive intra-alveolar hae- } \\
\text { morrhage, in addition }\end{array}$ \\
\hline$\stackrel{9 b}{9}$ & $5 \mathrm{dy}$. & 28 & 100 & $0 \cdot 70$ & + & 13 & - & 0 & $\begin{array}{l}\text { On IPPR; at necropsy mas- } \\
\text { sive intra-alveolar hae- }\end{array}$ \\
\hline 10 & $12 \mathrm{hr}$. & 40 & $4 \cdot 46$ & $0 \cdot 19$ & 0 & 21 & 0.35 & 0 & $\begin{array}{l}\text { morrhage only } \\
\text { Adrenal hypoplasia }\end{array}$ \\
\hline
\end{tabular}

$\mathrm{T}_{\min .}=$ minimum surface tension on surface balance; $\mathrm{SR}=$ stability ratio; $\mathrm{L}=$ deflation stability index; $\mathrm{HM}=$ hyaline membrane; RDS = respiratory distress syndrome; IPPR $=$ intermittent positive pressure respiration; $+=$ present; $0=$ absent; $-=$ not investigated. 


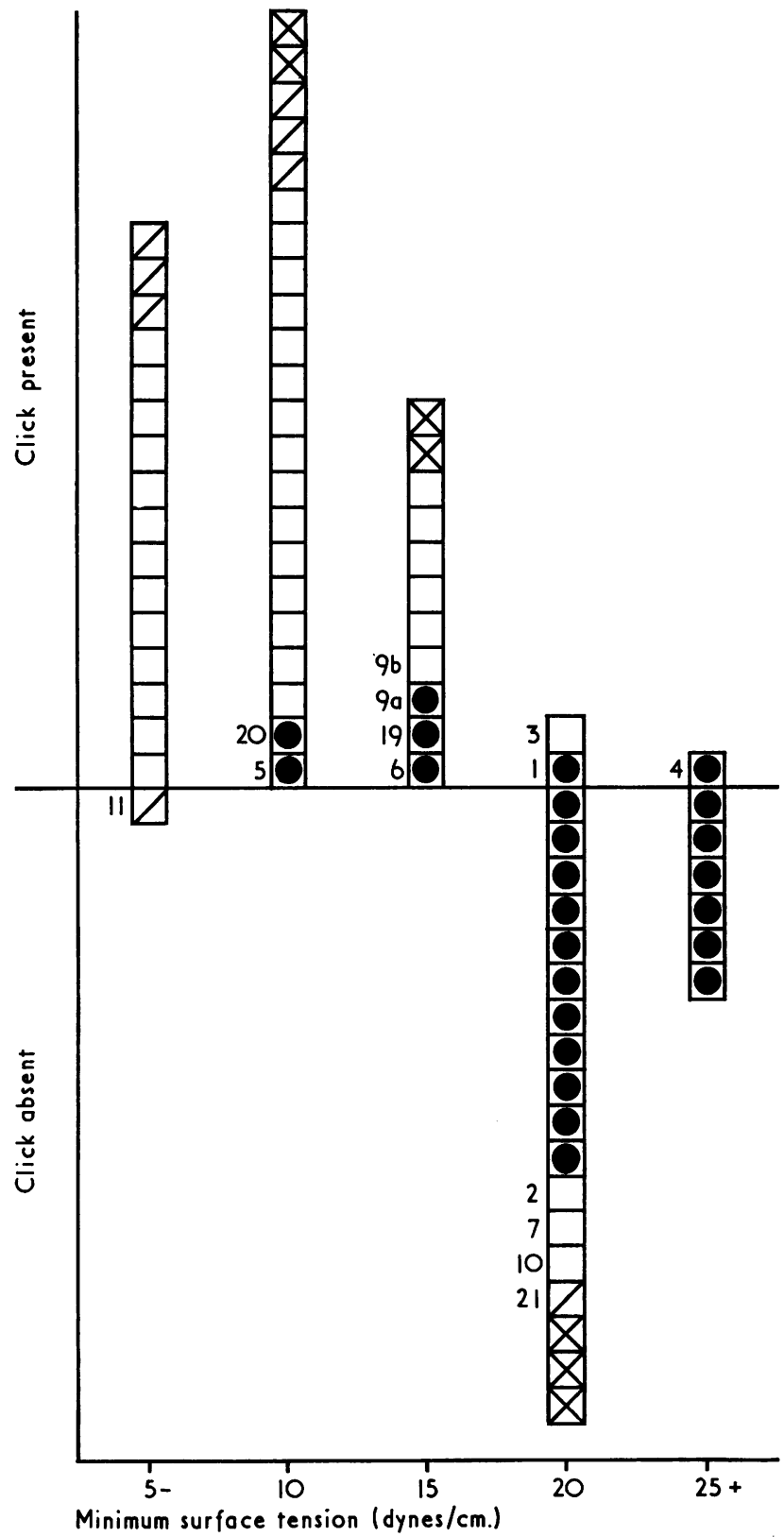

which did not click. Details of these 3 exceptions are included in Table II and are discussed later.

Fig. 3 relates bubble stability ratio to surface tension of lung extract in 49 cases. Of 31 cases where $T_{\min }$. was normal (15 dynes/cm. or less), SR was also normal in all except 2 . Of 18 cases where
$T_{\text {min. }}$ was abnormal (20 dynes/cm. or more), SR was also abnormal in all except 1.

Bubble clicking related to lung stability. Fig. 4 shows the results in 19 cases. Values for deflation stability index (L) fall into two groups; 


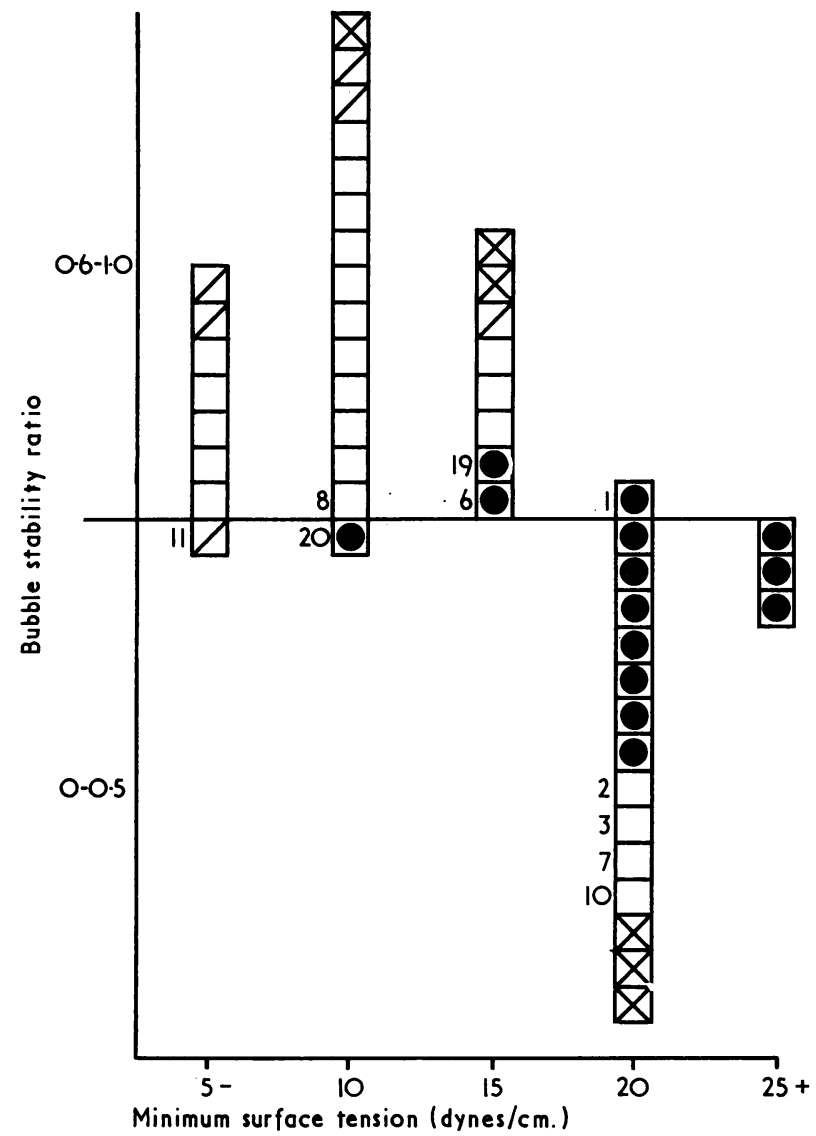

FIG. 3.-Minimum surface tension on surface balance vs. bubble stability ratio, in lung extracts from 49 perinatal deaths.

For key see Fig. 1.

in 11 cases the value for $\mathrm{L}$ was normal, $0 \cdot 7$ or above, and bubble clicking was present in all these. In 8 cases L was low, 0.4 or below, and in 7 of these bubble clicking was absent. The exception was Case 8, where the value for $L$ was 0.43 , though the other three parameters (see Table II) indicated normal lung surface properties. That in this instance the index $L$ failed to provide a true measure of the normality seemed likely, since the inflated lung retained, during deflation to $5 \mathrm{~cm}$. $\mathrm{H}_{2} \mathrm{O}$ pressure, well over half the maximum volume of air, and this standard $\left(V_{5} / V_{\max }>0.5\right)$ is an alter-

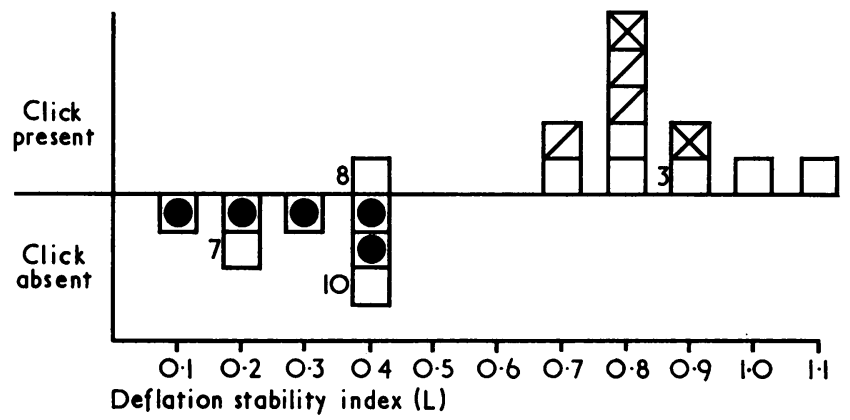

Fig. 4.-Deflation stability index $(L)$ vs. presence or absence of bubble clicking in lung extracts, in 19 perinatal deaths. For key see Fig. 1. 


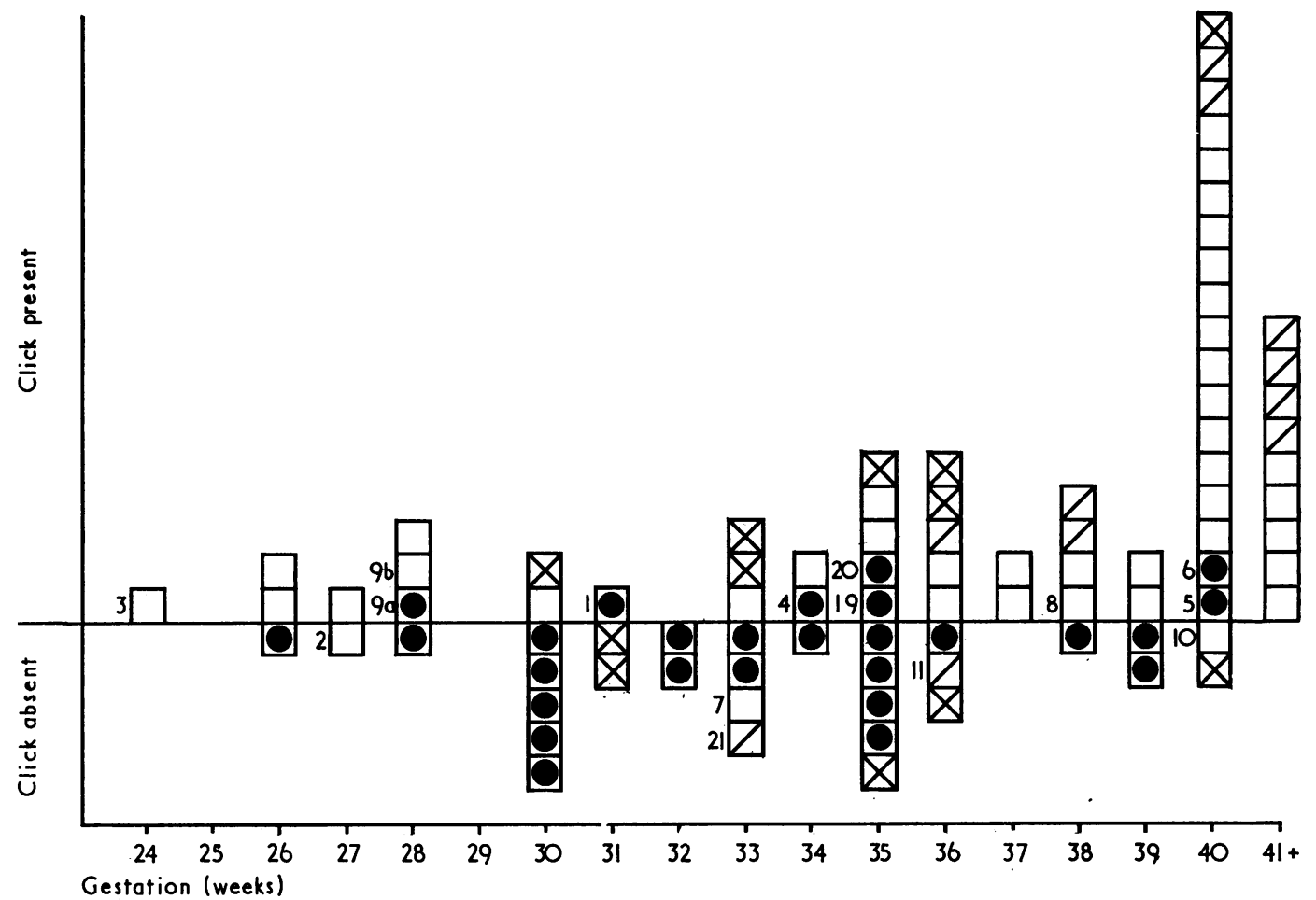

FIG. 5.-Presence or absence of bubble clicking in lung extracts from 90 perinatal deaths, according to gestation period. For key see Fig. 1.

native index of normality (Gruenwald, 1963a).

Bubble clicking in relation to gestation. Fig. 5 shows the results of testing for bubble clicking in 90 cases arranged according to length of gestation. Clicking was demonstrable in the majority of the cases without HM, including the most immature infants of 24-27 weeks' gestation.

Deficiency of surfactant in relation to pulmonary hyaline membrane. In liveborn cases where the lung histology showed hyaline membrane, deficiency of surfactant was frequently demonstrable. This was so whether the method for evaluating surfactant was bubble clicking (Fig. 1, 2), bubble stability (Fig. 1 and 3), or surface balance (Fig. 2 and 3). Likewise, the presence of HM was associated with instability of the air-inflated lung in the 5 cases in which this was tested (Fig. 4). Individual cases which fell outside this general concordance are detailed in Table II, and are discussed below.

Surfactant in hypoplastic lung. It is of interest to know whether conditions which lead to maldevelopment of the fetal lung also affect its surface activity. In this series, 5 cases of lung hypoplasia were seen and are detailed in Table III.

Bilateral lung hypoplasia was present in 3 cases associated with renal agenesis (Potter's syndrome), with or without other major defects. In the remaining 2 cases there was a large diaphragmatic hernia, leading to hypoplasia of the lungs from compression; in these cases the hypoplasia of the left lung was sometimes extreme, the lung being reduced in two instances (Cases 14 and 15) to only $1 \mathrm{~g}$. and $2 \mathrm{~g}$., as against an expected weight of about $30 \mathrm{~g}$.

Surface activity was tested in both lungs in the 2 cases with diaphragmatic hernia, and in one lung in the remaining 3 cases.

Normal surface activity was demonstrated in all except one of the tests carried out, including the 2 (Cases 14 and 15, Table III) where the hypoplasia was extreme. Only in one instance (Case 11) was there an equivocal result, with bubble clicking absent (and SR abnormal) despite a normal $\mathrm{T}_{\min .}$ value.

Surfactant in stillbirths. Of the 11 fresh stillbirths in the series, only 1 gave unequivocally 
TABLE III

Five Cases of Lung Hypoplasia

\begin{tabular}{|c|c|c|c|c|c|c|c|c|}
\hline $\begin{array}{l}\text { Case } \\
\text { No. }\end{array}$ & $\begin{array}{l}\text { Weight } \\
(\mathrm{kg} .)\end{array}$ & $\begin{array}{l}\text { Gest'n } \\
\text { (wk.) }\end{array}$ & $\begin{array}{l}\text { Age at } \\
\text { Death }\end{array}$ & $\begin{array}{c}\text { Associated } \\
\text { Defects }\end{array}$ & $\begin{array}{l}\text { Lung } \\
\text { Weight } \\
\text { Found } \\
\text { (g.) } \\
\end{array}$ & $\begin{array}{c}\text { Lung } \\
\text { Weight } \\
\text { Expected } \\
\text { (g.) }\end{array}$ & $\begin{array}{c}\text { Bubble } \\
\text { Click }\end{array}$ & $\begin{array}{c}\text { Tmin. } \\
\text { (dynes/ } \\
\text { cm.) }\end{array}$ \\
\hline 11 & $1 \cdot 48$ & 36 & Stillbirth & Multiple gross defects, including & $\mathbf{R}+\mathbf{L}=10$ & 37 & 0 & 7 \\
\hline 12 & $2 \cdot 15$ & 34 & $1 \mathrm{hr}$. & Multiple gross defects, including & $\mathbf{R}+\mathbf{L}=15$ & 47 & + & 16 \\
\hline 13 & $2 \cdot 50$ & 39 & $6 \mathrm{hr}$. & Renal agenesis & $R+L=17$ & 50 & + & 9 \\
\hline 14 & 3.06 & 40 & $9 \mathrm{hr}$. & Diaphragmatic hernia & $\left\{\begin{array}{l}R=10 \\
L=1\end{array}\right.$ & $\begin{array}{l}28 \\
28\end{array}$ & $\begin{array}{l}+ \\
+\end{array}$ & $\begin{array}{r}13 \\
5\end{array}$ \\
\hline 15 & $3 \cdot 55$ & 40 & $2 \mathrm{hr}$. & Diaphragmatic hernia & $\left\{\begin{array}{l}R=12 \\
L=2\end{array}\right.$ & $\begin{array}{l}30 \\
30\end{array}$ & $\begin{array}{l}+ \\
+\end{array}$ & $\begin{array}{r}10 \\
4\end{array}$ \\
\hline
\end{tabular}

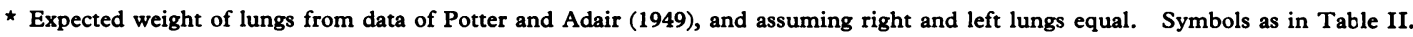

abnormal surfactant values, a stillbirth of 33 weeks' gestation (Case 21, Fig. 2 and 5). The remaining 10 gave normal results, if we include Case 11 (Fig. $1,2,3$, and 5) where $T_{\min }$. was normal, though bubble clicking was absent.

Of the 12 macerated stillbirths, 7 gave normal and 5 abnormal surfactant results. A failure to demonstrate normal surfactant in a macerated stillbirth clearly allows no conclusion as to the presence or absence of surfactant during fetal life. But the fact that normal surfactant can be demonstrated in many macerated stillbirths may sometimes prove relevant, as, for instance, in investigating perinatal death in diabetic pregnancy (see below, Cases 17 and 18, Table IV).

Surfactant in infants of diabetic mothers. The high incidence of neonatal deaths, often associated with hyaline membrane disease, gives particular interest to the lung surfactant findings in this group. The products of 4 diabetic pregnancies were investigated (Table IV). Two were macerated stillbirths (Cases 17 and 18), and in them normal surfactant values were found. In Case 19, where death occurred on the 2nd day, samples of lung from four different sites were examined for bubble $S R$ and clicking, with the variable results shown in Table IV, ranging from abnormal to normal. In Case 20, death occurred on the 3rd day; bubble SR was borderline normal, and bubble clicking and $T_{\min }$ value indicated normal surfactant.

\section{Discussion}

Bubble clicking vs. other parameters of lung surface activity. The results show that by the bubble clicking method lungs may be divided into a normal and an abnormal group, which with a few exceptions coincide with the normal and abnormal groups defined by measuring: (1) the stability

TABLE IV

Four Cases with Maternal Diabetes

\begin{tabular}{|c|c|c|c|c|c|c|c|c|c|}
\hline $\begin{array}{l}\text { Case } \\
\text { No. }\end{array}$ & $\begin{array}{l}\text { Gest'n } \\
\text { (wk.) }\end{array}$ & Age & $\begin{array}{l}\text { Method } \\
\text { of } \\
\text { Delivery }\end{array}$ & $\begin{array}{c}\text { Weight } \\
\text { (kg.) }\end{array}$ & $\begin{array}{c}\text { Bubble } \\
\text { SR }\end{array}$ & $\begin{array}{c}\text { Bubble } \\
\text { Click }\end{array}$ & $\begin{array}{c}\text { Tmin. } \\
\text { (dynes/ } \\
\text { cm.) }\end{array}$ & $\begin{array}{c}\text { Lung } \\
\text { Histology }\end{array}$ & Remarks \\
\hline 17 & 33 & $\begin{array}{c}\text { Stillborn } \\
\text { macerated }\end{array}$ & Vaginal & $2 \cdot 95$ & 0.64 & + & 15 & $\begin{array}{c}\text { Inhaled } \\
\text { squames } \\
++\end{array}$ & - \\
\hline 18 & 36 & $\begin{array}{c}\text { Stillborn } \\
\text { macerated }\end{array}$ & Vaginal & $2 \cdot 63$ & 0.71 & + & - & - & - \\
\hline 19 & 35 & $2 \mathrm{dy}$. & Caesarean & $3 \cdot 35$ & $\begin{array}{l}0.16 \\
0.14 \\
0.58 \\
0.52\end{array}$ & $\begin{array}{l}0 \\
+ \\
+ \\
+\end{array}$ & 14 & HM 4+ & $\begin{array}{l}\text { Severe maternal pre-eclamp- } \\
\text { sia; hydramnios; infant } \\
\text { apnoeic at birth, IPPR } \\
\text { given from outset }\end{array}$ \\
\hline 20 & 35 & $3 \mathrm{dy}$. & Caesarean & $2 \cdot 23$ & 0.54 & + & 12 & HM $3+$ & $\begin{array}{l}1 \text { previous stillbirth at } 38 \\
\text { wk.; hydramnios; caes- } \\
\text { arean section after onset } \\
\text { spontan. labour at } 35 \text { wk.; } \\
\text { infant apnoeic, respira- } \\
\text { tions established at } 4 \text { min.; } \\
\text { thereafter typical RDS; } \\
\text { IPPR from } 7 \text { hr. till death }\end{array}$ \\
\hline
\end{tabular}


ratios of bubbles, (2) the minimum surface tension of lung extract on the surface balance, or (3) the pressure-volume characteristics of the inflated lung.

Since to determine the presence or absence of bubble clicking takes only a few minutes, utilizes only a fraction of a gram of lung tissue, and needs no equipment other than a microscope, this simple method for characterizing the surface properties of lung has much to commend it.

There have been no previous human studies where bubble methods have been compared with other methods for evaluating surface properties of lung. In lungs from fetal lambs, a correlation between bubble SR, surface tension measured by Wilhelmy balance, and pressure-volume deflation index (L), was recorded by Howatt, Avery, Humphreys, Normand, Reid, and Strang (1965).

Relation of pulmonary hyaline membrane to lack of lung surfactant. Abnormal surface properties in a lung from a liveborn infant, as defined by any of four methods studied, proved in this series to be associated usually with the presence of pulmonary hyaline membrane. This is in general agreement with previous reports. Avery and Mead (1959) were the first to examine lung extracts from cases of hyaline membrane disease, and to demonstrate abnormal surface properties on the Wilhelmy balance. Gruenwald (1965) investigated the stability of lungs on inflation in a large series of 315 perinatal deaths. Among newborn infants in whom death had taken place between 6 and 24 hours, there was an almost perfect correlation between poor stability of expansion (low $\mathrm{L}$ value) and the presence of HM. Among deaths occurring before 6 hours, however, lungs which showed poor stability did not always show HM, and it was suggested that the explanation was that there had been insufficient time for membrane to form. Conversely, among those deaths later than 24 hours where HM was present, a few lungs showed normal stability, perhaps because a supply of surfactant was by then beginning to appear. Reynolds, Orzalesi, Motoyama, Craig, and Cook (1965) studied lungs from 30 fatal cases of RDS; only 2 gave extracts with normal surface tension values, and both cases had died on the third day of life with intracranial haemorrhage at a time when they were thought to be recovering from RDS. Pattle, Claireaux, Davies, and Cameron (1962) studied 6 fatal cases of RDS, measuring the SR of bubbles expressed from the lungs; this was abnormal in all $6, \mathrm{HM}$ being present in 5 , but absent in the 1 case where death had taken place earlier than 6 hours.

In a minority of the cases in our series HM was present histologically despite evidence of normal surface activity, or conversely, it was absent despite evidence of deficient surface activity. These individual cases may therefore be considered in the light of such factors as the length of survival, the degree of prematurity, and the existence of other pulmonary or non-pulmonary disorders (Table II).

Case 1 had RDS, which ran a typical course except that death occurred unusually late, on the 4th day. $\mathrm{HM}(2+)$ was present, and $\mathrm{T}_{\min }$. was abnormal, but both bubble methods gave a normal result. Possibly by the 4 th day surfactant may have been appearing.

Case 2 was of 27 weeks' gestation, and died at 2 hours. Surfactant was absent (by three methods) in a histologically very immature lung with no HM; it is conjectural whether HM would have been formed had survival been longer.

Case 3 was of 24 weeks' gestation surviving 7 hours, and illustrates borderline lung surface properties, with normal bubble click and $\mathrm{L}$ values, slightly abnormal bubble $S R$ value, and abnormal $\mathrm{T}_{\min \text {. value. }}$

Case 4 was the only example of clinically typical RDS with proven HM and a lack of surfactant according to $T_{\min }$. value, but in which bubble clicking was nevertheless demonstrated, a discordance which can only be left as unexplained.

Case 5 was diagnosed during life as cyanotic heart disease, and died on the 3rd day. Necropsy showed a transposition of the great vessels, but, unexpectedly, in the lungs $\operatorname{HM}(2+)$ was also found, though surfactant (by two methods) was normal. The possibility is raised that HM can, on occasions, result from pulmonary oedema caused by heart failure. However, in the only publication where the presence of pulmonary HM was related to congenital heart disease, Shanklin (1959) found atrial septal defect to be the commonest heart lesion, while transposition was not mentioned.

Cases 6, 7, 9a, and $9 b$ all showed massive intraalveolar haemorrhage as the main pathological finding. Surfactant was normal in 3 of these 4 cases, and abnormal in 1. HM was present $(2+)$ in 1 of the cases; it was also minimally present $(1+)$ in one of twins (Case 9a), though absent in the other twin (Case 9b). No conclusions can be drawn from these scanty facts as to the interrelations between pulmonary haemorrhage, hyaline membrane, and deficiency of surfactant.

Case 10 was a large full-term baby, born by caesarean section on account of fetal distress. Breathing was normal initially, but at 1 hour there was cyanosis and grunting respiration, though he did not appear gravely ill. He died suddenly at 
12 hours. The main post-mortem finding was conspicuous adrenal hypoplasia, the adrenals weighing 2 g. (expected weight 12.5 g.). Lung surfactant was deficient (by four methods), but the cause of this and its relation to the adrenal hypoplasia was obscure, the lung histology showing no HM but merely some polymorph infiltration.

Cases 19, 20 (Table IV), see below.

Surfactant in hypoplastic lung. The finding of normal surfactant values in hypoplastic lungs (Table III), whether the hypoplasia was associated with renal agenesis (Potter's syndrome), or with occupation of the thorax by abdominal viscera, is of some interest, as 'experiments of Nature' such as these may perhaps shed light on the mechanism of surfactant deficiency in RDS. It has been argued (Cohen, Weintraub, and Lilienfeld, 1960; Reynolds et al., 1965; Gruenwald, 1966) that RDS, and the deficiency of surfactant demonstrable in fatal cases, may be a consequence of some prenatal interference with pulmonary metabolism. It is therefore worth noting that hypoplastic lungs showed no deficiency of surfactant, even though subjected in two instances (Cases 14 and 15) to such gross interference with development that the lung was reduced to $7 \%$ or less of its normal substance.

Surfactant in infants of diabetic mothers. In Avery and Mead's (1959) series, the product of one diabetic pregnancy was reported: a $3 \mathrm{~kg}$. stillbirth, the lungs showing lack of surfactant on the surface balance. Apart from this single case, facts are lacking about lung surfactant in this group of infants, so that our findings in $\mathbf{4}$ cases (Table IV) have been fully set out.

The two stillbirths (both macerated, Cases 17 and 18) had normal surfactant values, a fact which therefore lends no support to a congenital deficiency of surfactant as an explanation of RDS in infants of diabetic mothers.

Cases 19 and 20 presented several similarities; both were delivered by caesarean section, and both required intensive resuscitation before breathing was established after birth. Respiratory failure then followed, and was unsuccessfully treated with IPPR. In the lungs, hyaline membrane was conspicuous. Lung surfactant estimated by surface balance was normal in both; and estimated by bubble SR it was borderline between normal and abnormal in Case 20, while in Case 19 four different samples of lung tissue tested gave different results varying from normal to abnormal. These equivocal but mainly normal surfactant results in our two cases of hyaline membrane disease associated with maternal diabetes contrast with the other cases of hyaline membrane disease in our series, in which surfactant deficiency was rarely absent. Further data are required to determine whether hyaline membrane disease occurring in infants of diabetic mothers possesses any consistent distinguishing features.

\section{Summary}

Surface properties of lungs from 90 perinatal deaths have been evaluated by four methods: (1) bubble stability ratio, (2) bubble clicking, (3) surface balance, and (4) pressure-volume curve of airinflated lung.

By each of the four methods lungs could be divided into normal and abnormal groups, and in only a minority of cases did the different methods fail to give concordant results. The bubble-clicking method is simple, rapid, requires only a fraction of a gram of tissue, and no special equipment.

Most of the lungs which lacked normal surface properties also showed hyaline membrane, if the infant had been liveborn and had survived more than 2 hours. Exceptions to this general rule are discussed.

Lung surfactant findings are presented in two particular groups of cases: congenital hypoplasia of lung, and infants of diabetic mothers.

We are grateful to Dr. R. E. Pattle who demonstrated his techniques to us. This work was supported by a Medical Research Council Grant, and B.T.N. held a British Council scholarship.

\section{REFERENCES}

Avery, M. E., and Mead, J. (1959). Surface properties in relation to atelectasis and hyaline membrane disease. Amer. F. Dis. Child., 97, 517.

Clements, J. A. (1957). Surface tension of lung extracts. Proc. Soc. exp. Biol. (N.Y.), 95, 170.

Cohen, M. M., Weintraub, D. H., and Lilienfeld, A. M. (1960). The relationship of pulmonary hyaline membrane to certain factors in pregnancy and delivery. Pediatrics, 26, 42.

Gruenwald, P. (1963a). Normal and abnormal expansion of the lungs of newborn infants obtained at autopsy. Lab. Invest., $12,563$.

(1963b). A numerical index of the stability of lung expansion. F. appl. Physiol., 18, 665.

(1965). Pathology of the respiratory distress syndrome. Arch. Path., 80, 30.

- (1966). Pulmonary surfactant and stability of aeration in young human fetuses. Pediatrics, 38, 912.

Howatt, W. F., Avery, M. E., Humphreys, P. W., Normand, I. C. S., Reid, L., and Strang, L. B. (1965). Factors affecting pulmonary surface properties in the foetal lamb. Clin. Sci., 29, 239.

Pattle, R. E. (1958). Properties, function and origin of the alveolar lining layer. Proc. roy. Soc. $B, 148,217$.

(1960). The cause of the stability of bubbles derived from the lung. Phys. in Med. Biol., 5, 11.

(1965). Surface lining of lung alveoli. Physiol. Rev., 45, 48. -, Claireaux, A. E., Davies, P. A., and Cameron, A. H. (1962). Inability to form a lung-lining film as a cause of the respiratorydistress syndrome in the newborn. Lancet, $2,469$.

Potter, E. L., and Adair, F. L. (1949). Fetal and Neonatal Death, 2nd edn. University of Chicago Press, Chicago, Illinois.

Reynolds, E. O. R., Orzalesi, M. M., Motoyama, E. K., Craig, J. M., and Cook, C. D. (1965). Surface properties of saline extracts from lungs of newborn infants. Acta paediat. (Uppsala), 54,511.

Shanklin, D. R. (1959). Cardiovascular factors in development of pulmonary hyaline membrane. Arch. Path., 68, 49. 